\title{
Relationship between welfare staff and organizational commitment in the control center of the Central Registration Office
}

\author{
Ali Nazeri ${ }^{a^{*}}$, Hadi Meftahi ${ }^{b}$, and Reza Kianipour ${ }^{c}$ \\ ${ }^{a}$ Department of Industrial Engineering, Damavand Branch, Islamic Azad University, Dmavand, Iran \\ ${ }^{b}$ Department of industrial management, Payame Noor Universtiy, PO BOX 19395-3697, Tehran, Iran \\ ${ }^{c}$ Department of Management, Arak Branch, Islamic Azad University, Arak, Iran

A R T I C L E I N F O AB S T R A T

Article history:

Received October 20, 2011

Received in Revised form

February, 20, 2012

Accepted 8 April 2012

Available online

April 122012

Keywords:

Organizational commitment

Work locus of control

Staff's wellbeing

Normative commitment

Continuance commitment

\begin{abstract}
The aim of this research is to analyze the role of the staff's wellbeing stated as independent variable and the work locus of control as the moderator factor associated with the organizational commitment and the staff's wellbeing. To accomplish the objective, we used regression analysis. The research focuses on the one's ability to predict the staff's wellbeing and it studies the effects of the work locus of control as a moderator on the organizational commitment. Findings of the research show that the staff's wellbeing maintains a negative relationship with the continuance commitment and a positive relation with the affective and normative commitments. Moreover, the impact of the work locus of control, as moderator, on the relationship between the staff's wellbeing and their organizational commitment relational and has some necessities. Thus, the findings of the research are in a state of continual changes.
\end{abstract}

(c) 2012 Growing Science Ltd. All rights reserved.

\section{Introduction}

One of the necessary requirements for any society to become a developed country is to have organizations with proper and positive performance. Each organization, in turn, has its own aims and purposes and in order to reach them, the organization needs the staff's commitment and their responsibility towards their organization. Therefore, the organizational commitment is one of the most important issues heading those who study management. Surly, organizational commitment requires some necessities, which will, in turn, help its accomplishment, more properly. One of the necessaries is the staff's wellbeing or paying attention to the staff's conditions of living and its betterment, which is one the basic responsibilities of human resource management, it is also considered as a set of actions which help solving the staff's problems. Thus, organizations perform a variety of different tacks for the betterment of staff's conditions of living.

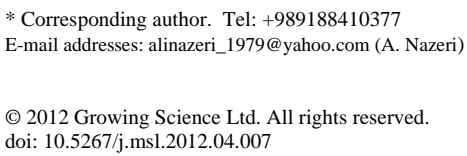


According to Morhad and Grifin (1995) organizational commitment is an important factor in understanding the staff's organizational behavior and is also a good predictor for forecasting the rate of the staff's willingness to stay in the job. Commitment and loyalty like the staff's satisfaction have similar connotations, which will consequently affect behaviors like alteration and absence. Moreover, commitment and loyalty can have fruitful and positive results. In other words, those employees who are more loyal to the organization possess a great deal of discipline, will stay in the job and work more than other do. Thus, managers should encourage the staff to be loyal in organizations, to accomplish this aim they have to use the staff's views in their decision-making and they should also provide them with security within the organization's environment.

Lo and Ramayah (2011) studied mentoring and job satisfaction in Malaysian small and medium enterprises (SMEs) by gathering the necessary data required to examine the relationship between mentoring and employees' job satisfaction among staffs from small and medium enterprises in Malaysia. In their survey, they designed a questionnaire and distributed among 200 people among executives of the middle and lower management level from the 21 selected SMEs. Their results showed that there was a positive relationship between career mentoring and all dimensions in job satisfaction such as co-workers, job itself, promotion and supervisors. However, they claimed no substantial relationship between psychosocial mentoring and three aspects of employees' job satisfaction, namely co-workers, job itself, and promotion.

Involvement means the person's willingness to be responsible toward whatever his/her job requirements. Commitment and involvement depend on the personal, group, and organizational factors (Hodgkinson \& Ford, 2010). The concept of commitment is one of the basic issues in management textbooks. It is also one of the factors that organizations is founded and according to which the staff are evaluated. Most of the managers believe that the staff's commitment would greatly affect the organization (Robbins, 2010).

It is worth mentioning that the staff should take the responsibility of whatever they do to be satisfied with their own status. In other words, the better employees accomplish their responsibilities, the better they could meet their commitments. On the contrary, when employees do not take responsibility of their actions, they would reach a state which researchers call encountered distress. Thus, employees continue to be frustrated and lose their hopes and they might feel that they cannot change anything unwanted in the organization's environment.

Chen et al. (2006) investigated organization communication, organizational commitment, job stress, and job performance of accounting professionals for two countries of Taiwan and United States. They found out that there was not a substantial change in stress and communication levels between two countries but organizational commitment and performance levels were higher in the USA. They also reported that higher levels of organizational communication possibly could lead to higher levels of organizational commitment and job performance in both countries. The other interesting results of their studies indicated that stress levels were not related to either organizational communication or job performance. According to what have been argued, when employees feel that they can control whatever in their lives and business, feelings of happiness and satisfaction will haunt their minds. Modern psychology calls the mentioned hypothesis work locus of control. Hatton et al. (1999) enumerated six factors associated with employees' well being, which are as follows,

The ability to control one's own deeds, feeling of being protected and secured, personal control over the work, having the ability to positively converse with other workers, having a clarified and reasonable role in organization, and being able to overcome the contradictions in the face of changes.

In some cases, "wellbeing” has been defined as the ability to tolerate physical and psychological pressures in the organization's environment. Finally, it should also be stated that the employees' well being can be considered as the foundation for the employees' commitment. 


\subsection{The Staff's wellbeing}

According to Meyer and Smith (2001), the staff's wellbeing has got the following characteristics: Manageable attitude having authority over one's job, feeling of being secured, positive relationship with other employees and performing a positive role in organizational changes.

\subsection{Work Locus of Control}

The work Locus of control plays an important role when employees encounter stressful conditions. The work locus of control is a kind of generalized anticipation, which could strengthen the events by deploying personal control over those events.

\subsection{Organizational Commitment}

Organizational commitment has three characteristics including the willingness to stay or remain as a member of a certain organization, having a whole hearted inclination to the organization and deeply believing in the organization's objectives and values more over commitment can be viewed as the staff's loyalty to the organization. This could be achieved by expanding the employees' involvement in the decision-making, it also increases the staff's attention to the organization and its success.

\subsection{Affective Commitment}

As we already explained, affective commitment has been defined as the staff's deep belief in the organization's objectives, working in line with its aims/ values, and strong inclination to stay there. The personal traits of those who possess or those who have strong commitments are: extra-work for the organization without claiming any salary, taking the organizations' issues/problems as one's own, and having a strong inclination toward the organization (Meyer et al., 1993).

\subsection{Continuance Commitment}

Continuance commitment is the staff's willingness to continuously contribute to organization, which includes: to deeply believe in the fact that learning the organization would generate devastating problems in the employees' personal lives, to internalize the fact that by learning the organization, there would be no other choices for employment in other organizations, etc. (Meyer et al., 1993).

\subsection{Normative Commitment}

Normative Commitment can be defined as one's responsibility towards the organization. Besides, it can be associated with a set of internalized norms/regulations, performed to accomplish predetermined aims/purposes of the organization. The following characteristics hold for those with normative commitment: believing that being loyal to the organization is a normal activity, internalizing the fact that an employee should stay in the job till retirement and to deeply believe that an employee should sacrifice herself/himself for the sake of the organization (Allen \& Mayer, 1996).

\section{Theoretical foundation of the research}

In the literature of organizational behavior, Allen and Mayer (1990) differentiated and enumerated different kinds of loyalty as affective commitment, normative commitment, and continuance commitment.

Psychological state of each employee will affect the mentioned categories of commitment and causes some changes among them. Organizational commitment is a kind of outlook, which demonstrates the employee's rate of loyalty and their willingness to stay in the institution. Moreover, the employee's well being is the basis in generating the staff's commitment and as it already explained it can be described as the staff's ability to tolerate physical-psychological pressures in the organization. 
There are several studies associated with the work locus of control and its effects in the job. These works indicate those employees who were regarded by the work locus of control as introvert, stayed in the job more than others, their performance was better than others, were more satisfied with their jobs, and took the responsibility of their actions more than others did.

The work locus of control, which acts as a mediator between the staff's wellbeing and the organizational commitment can also be analyzed and studied in the following model,

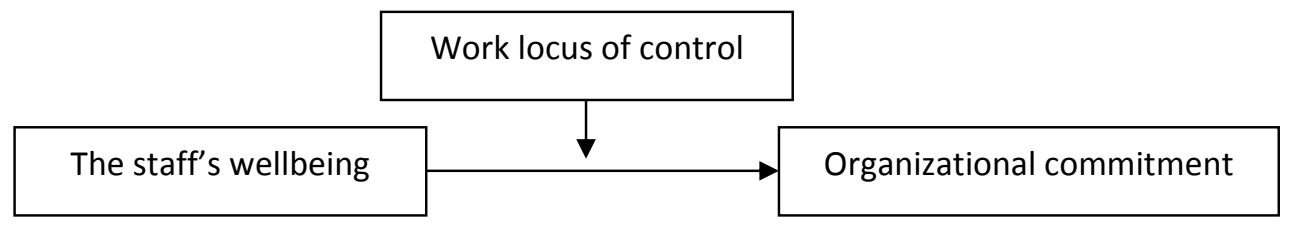

\section{Research hypotheses}

Analytical Model of the Research

I) The staff's wellbeing has a positive relationship with their normative and affective commitment, and a negative relation with the staff's continuance commitment.

II) work locus of control acts as a moderator between the staff's wellbeing and their organizational commitment.

\subsection{Aims and purposes of the research}

I. studying and analyzing the relationship between the staff's wellbeing and their organizational commitment for a distance learning university located in the province of Ilam, Iran called Payam-eNoor university

II. Determining the role of the work locus of control in generating organizational commitment among the Payam-e-Noor's staff.

III. Clarifying the relationship between the staff's wellbeing and organizational commitment, and also determining the moderator role of work locus of control in generating a kind of relation between the staff's wellbeing and the organizational commitment.

\subsection{The Research's Methodology}

As it was already mentioned, the research's aim is to determine the relationship between the staff's wellbeing and the organizational commitment, the method that was adapted to collect descriptive data was a correlation one- specifically named as regression analysis.

Descriptive- analytical statistics were used in order to study the relationship between our variables and the hypotheses. The required data were collected by using questionnaire and the mentioned relationship was analyzed by SPSS software. Moreover, the regression analysis was used for the test of our hypotheses. The effect of Moderator role of the work locus of control was analyzed by hierarchical regression. In other words, during the first the work locus of control was entered into the Model. Then, its direct effect on dependent variable was analyzed. In the second phase, the work locus of control and the independent variable were entered into the model to analyze their indirect effect on the dependent variable. The researcher would be allowed to use linear regression if the necessary assumptions of any linear regression hold. The target population $(\mathrm{N}=200)$ of the research consists of the employees of the payame-e- Noor university of Ilam. We did not collect our target population by random sampling because the population was not so enlarged. Thus, we considered all of the university's staff as our target population. About two hundred questions were prepared and 
given to the employees, but only hundred forty eight (148) were completed, accordingly our target population was reduced to (148) on which our analysis is based.

\subsection{The Intrinsic strength/value of the Research}

The Cronbach alpha was calculated by SPSS and was reported as 0.815 , which is well above the minimum required and it shows the research's high validity. Table 1 shows different Cronbach alpha calculated for each part of the survey.

\section{Table 1}

Cronbach alpha

\begin{tabular}{llcc}
\hline Raw & Dimension & Related Questions & Tm Cronbach alpha \\
\hline 1 & Affective commitment & $1-5$ & 0.789 \\
2 & Continuance commitment & $6-10$ & 0.708 \\
3 & Normative commitment & $11-13$ & 0.721 \\
4 & Work locus of control & $14-19$ & 0.705 \\
5 & Staff's wellbeing & $20-29$ & 0.875 \\
\hline
\end{tabular}

\section{Finding of the research}

The first hypothesis stated, “The staff's wellbeing has a positive relation with their normative and affective commitment and a negative relation with the staff's continuance commitment”. The coefficient regression about the relationship between the staff's wellbeing and the dependent variable of affective commitment is .519 with a meaningful level of sig $=0.000<0.05$. Thus, the zero hypothesis $\left(\beta_{1}=0\right)$ is rejected. In other words, the researcher's claim, which stated that the staff's wellbeing has a positive relation with their affective commitment is accepted with \%95 percent level of assurance.

The coefficient regression on the relationship between the staff's wellbeing and the dependent variable of normative commitment is .258 with meaningful level of sig $=0.000<0.05$. Thus, the zero hypothesis $\left(\beta_{1}=0\right)$ is rejected. In other words, the researcher's claim, which stated that the staff's wellbeing has a positive relation with the normative commitment is accepted with \%95 percent level of assurance. The coefficient regression about the relationship between the staff's wellbeing and the dependent variable of continuance commitment is -.402 with meaningful level sig $<0.05$. Therefore, the zero hypothesis $\left(\beta_{1}=0\right)$ is rejected and it can be said that the research's claim, which states that the staff's wellbeing affects their continuance commitment.

The staff's wellbeing has a positive/meaningful relationship with affective and normative commitments, but the mentioned relation when applied to continuance commitment is a negative one. According to what has been stated, the staff's wellbeing has a positive correlation with the organizational commitment. The reason why there is a positive relationship between the staff's wellbeing and the affective and normative commitment maybe the fact that those employees with a good level of welfare are more responsible towards the norms and regulations, from a long-lived involvement with the organization, and are more loyal to the organization. They will also generate a positive outlook toward the organization's issues and consequently this optimism leads them to develop a kind of affective commitment. According to the recent studies, the commitment to continue one's activities in an organization is not just because of the emotional ties, it may also be because if the difficulties heading the staff after learning the organization. Thus, this kind of commitment can be stated as a consequential one and more welfare yields a low commitment.

The second hypothesis stated, "work locus of control plays as a moderator between the staff's wellbeing and their organizational commitment." The direct effect of work locus of control on the 
staff's commitment is rejected based on $\beta=0.109$, sig $=0.169>0.05$, during the second step its indirect, positive effect on the staff's on the staff's wellbeing and affectional commitment is strongly affirmed according to: $\beta=251$, sig $=0.009<0.05$. Therefore, the research's hypothesis is not rejected, because the moderator variable does not have an indirect and direct influence, simultaneously.

The direct impact of the work locus of control on normative commitment cannot be rejected according to $\beta=451$, sig $=0.000<0.05$, and in the second step the positive and direct effect of the work locus of control on the staff's wellbeing and normative commitment cannot be rejected according to $\beta=0.410$, sig $=0.033<0.05$. This hypothesis is also affirmed. The direct effect of the work locus of control on the continuance commitment is strongly confirmed according to $\beta=-0.73$, sig $=0.039<0.05$, during the second step the negative and indirect effect of the work locus of control on the staff's wellbeing and the continuance commitment is also confirmed considering $\beta=0.345$, sig $=0.014<0.05$. Thus, the hypothesis would be accepted, because the work locus of control variable works both as a direct and an indirect moderator.

\section{Conclusion}

Findings of the research show that the work locus of control- as a psychological variable- cannot always play a moderator role in generating an organizational commitment. In some researches, this role was confirmed and in other works, this impact was rejected. These contradictory findings/results show that there is no clear and unifying definition for the measurement of the work locus of control. These contradictory findings can also be the result of our way of sampling the target population, in other works, employees with internal work locus of control in comparison to those with external work locus of control, are more sensitive to the Social demands.

\section{References}

Chen, J.C., Silverthorne, C., \& Hung, J.Y. (2006). Organization communication, job stress, organizational commitment, and job performance of accounting professionals in Taiwan and America. Leadership \& Organization Development, 27(4), 242-249.

Cronbach, L. J. (1951). Coefficient alpha and the internal structure of tests. Psychometrika, 16(3), 297-334.

Hatton, C., Emerson, E., Rivers, M., Mason, H., Mason, L., Swarbrick, R., Kiernan, C., Reeves, D., \& Alborz, A. (1999). Factors associated with staff stress and work satisfaction in services for people with intellectual disability. Journal of Intellectual Disability Research, 43(4), 253-267.

Likert, R. (1932). A Technique for the Measurement of Attitudes. Archives of Psychology, 140, 1-55.

Lo, M. C., \& Ramayah, T. (2011). Mentoring and job satisfaction in Malaysian SMEs. Journal of Management Development, 30(11), 427-440.

Meyer, J. P., Allen, N. J., \& Smith, C. A. (1993). Commitment to organizations and occupations: Extension and test of a three-component conceptualization. Journal of Applied Psychology, 78, 538-551.

Meyer, J. P., \& Allen, N. J. (1997). Commitment in the Workplace: Theory, Research, and Application. Thousand Oaks, CA: Sage.

Meyer, J. P., \& Allen, N. J. (1991). A three-component conceptualization of organizational commitment. Human Resource Management Review, 1, 61-89.

Meyer, J. P., \& Smith, C. A. (2001). HRM practices and organizational commitment: Test of a mediation model. Canadian Journal of Administrative Sciences, 17, 319-331.

Moorhead, G. \& Grifin, R.W. (1995). Organizational Behavior: Managing People and Organizations. $4^{\text {th }}$ ed., Houghton Mifflin.

Hodgkinson, G.P., \& Ford, J.K. (2010). International Review of Industrial and Organizational Psychology. Wiley, 25.

Robbins, S.P. (2010). Organizational Behavior. Prentice Hall; $14^{\text {th }}$ ed., ISBN-10: 0136124011. 